\title{
The Benefits of Physical Activity in Children and Adolescents with Epilepsy: A Systematic Review
}

\author{
Loyane de Fátima Svierkovski $^{1} \quad$ Angelica Miki Stein ${ }^{1,2}$ Timothy Cavazzotto ${ }^{1}$ Ana Carolina Paludo ${ }^{1}$ \\ ${ }^{1}$ Department of Physical Education, Universidade do Centro-Oeste do \\ Paraná, Guarapuava, Brazil \\ 2 Human Performance Research Group, Technological Federal \\ University of Paraná, Curitiba, Paraná, Brazil \\ Address for correspondence Ana Carolina Paludo, Department of \\ Physical Education, Universidade do Centro-Oeste do Paraná, \\ Guarapuava 85040-167, Brazil (e-mail: anacpaludo@gmail.com). \\ J Pediatr Epilepsy 2021;10:97-103.
}

\begin{abstract}
Keywords

- adolescents

- children

- epilepsy

- exercise

- physical activity

The aim of this study was to review the literature about the effect of physical activity intervention in children and adolescents with epilepsy. Articles were searched in the central electronic databases of MEDLINE, Embase, PsycAriticles, and CINAHL for the following keywords: "epilepsy," "seizure," "physical activity," "physical exercise," "exercise therapy," "sport," using the Boolean operator "AND" and "OR." The quality of the selected articles was evaluated by the Physiotherapy Evidence Database scale. Out of the 22 articles selected, 18 did not involve intervention or did not have pre- and postresults and therefore were excluded from the study. The remaining four were studies from Canada and Korea which comprised two long-period interventions and were included in the analysis. Both programs demonstrated a positive effect of physical activity on variables related to psychological well-being and cognitive function. All the four articles demonstrated a lower score of quality. In conclusion, reviewed studies suggest that physical exercise program induces some benefits in children and adolescents with epilepsy. However, the noncontrolled trials and the varied analyses (quantitative vs. qualitative) make it difficult to establish a consensus about benefits of physical activity in epilepsy.
\end{abstract}

\section{Introduction}

Epilepsy is a chronic neurological condition characterized by the recurrence of unprovoked seizures, as a result of abnormal and excessive electrical discharges from neurons of the central nervous system. ${ }^{1}$ It can be caused by a genetic disorder, acquired brain injury (e.g., trauma or stroke), ${ }^{1,2}$ or in the first year of life due to immaturity of the brain. ${ }^{3}$ Epileptic seizures can be classified as focal or generalized, which can result in changes in the neural networks. ${ }^{4}$

Prevalence of epilepsy in children and adolescents in the developed world is $\sim 3.2$ to 5.5 per $1,000 .^{5}$ In children 3 to 10 years of age, the most common epilepsy type was generalized, while in those 10 to 18 years of age, it was focal, similar to the epileptic adult population. ${ }^{4}$ For fear of occur-

received

December 15, 2020

accepted

January 27, 2021

published online

March 10, 2021

rence of epileptic seizures, children and adolescents with epilepsy tend to reduce their participation in the sports program and exercise activities. They are consequently classified as inactive or less physically active, ${ }^{3}$ thereby having lower cardiorespiratory fitness levels ${ }^{6}$ compared with people without it. However, studies showed that seizures during exercise are uncommon. ${ }^{7,8}$ Participation in sports and physical activities is encouraged, especially at young ages, as they can act as a protective factor against seizures ${ }^{7}$ and psychosocial aspects such as increased self-esteem, socialization, and decreased comorbidities related to epilepsy. ${ }^{9}$

The recommendations reported in the literature for sports practice for people with epilepsy classify sports as high risk, moderate risk, low risk, and no risk of seizure occurrence during the event. ${ }^{7}$ However, this classification takes into

(c) 2021. Thieme. All rights reserved. Georg Thieme Verlag KG, Rüdigerstraße 14, 70469 Stuttgart, Germany
DOI https://doi.org/ 10.1055/s-0041-1725991. ISSN 2146-457X. 
account the sports' specific individual characteristics or circumstances for practice based on data evaluation, speculation of previous studies, and common sense. ${ }^{7}$ A systematic review described the recommendations for physical exercise protocols based on animal studies. As the main finding, the authors pointed out that resistance training proved to be more effective in treating epilepsy in rats, and protocols of long duration and moderate to high intensity were demonstrated to be more effective when compared with their counterparts. ${ }^{10}$

A previous study reported that only 2 of the 400 adults (less than $0.5 \%$ ) had seizures during physical activity. ${ }^{11}$ Another study concluded that exercise and sports may not trigger seizures in children and adolescents with epilepsy during physical activity at school. ${ }^{12}$ Due to the lack of knowledge of the disease, fear, overprotection, and other reasons, people with epilepsy are less inclined to exercise. ${ }^{12}$

This study was undertaken to review the literature about the impact of physical activity intervention in children and adolescents with epilepsy. Moreover, we aimed to describe design characteristics (e.g., type of exercise, duration, and intensity) and the effectiveness of these interventions. The results of this review may help support future interventional studies and assist physical education professionals in the prescription and guidance of exercises in children and adolescents with epilepsy.

\section{Methods}

\section{Protocol}

The systematic review followed the Preferred Reporting Items for Systematic Reviews and Meta-Analyses statement guidelines $^{13}$ and the PICOS model for the definition of the inclusion criteria: P (Population): "children and adolescents"; I (Intervention): "physical activity, sports or therapeutic exercises interventions"; C (Comparators): "variable results presented pre- and postinterventions"; O (Outcome): "effect or not on variables evaluated"; S (Study design): "interventional." 14

\section{Search Strategy}

Searching included four relevant electronic databases: MEDLINE (accessed by PubMed), Embase, Psycarticles, and CINAHL. Medical Subject Heading terms, if available in PubMed, were used. The following keywords were applied: "epilepsy," "seizure," "physical activity," "physical exercise," "exercise therapy," "sport," using the Boolean operator "AND" and "OR."

\section{Eligibility Criteria}

Only studies performed in children and adolescents, with exercise intervention and with pre- and postintervention assessments were included, with no restriction of sex, physical fitness, or level. Review, meta-analysis, and case study were excluded.

\section{Screening and Selection}

The search for articles was conducted between April and May 2020 by one independent evaluator. The studies were selected by title, abstract, and relevance. Duplicate studies, manuscript published as notes, case studies, reviews, and books, and those studies that did not meet the inclusion criteria were excluded. All publications, regardless of the year of publication, were considered for initial analysis.

\section{Quality and Risk of Bias Assessment}

One investigator evaluated the methodological quality of the included studies. The PEDro scale was used to assess the risk of bias which evaluates the quality of trials, especially in physical therapy and rehabilitation studies. PEDro scale contains 11 criteria: eligibility criteria, random allocation, concealed allocation, similarity at baseline, participants blinding, therapist blinding, assessor blinding, adequate follow-up ( $>85 \%$ follow-up for at least one key outcome), intention-to-treat analysis, between-group statistical comparison for at least one key outcome, and point and variability measures for at least one key work. Each item, except the first criterion, corresponds to one point and a study is graded as: 9 to 10 excellent, 6 to 8 good, 4 to 5 fair, and $<3$ poor quality. ${ }^{15}$

\section{Results}

\section{Search Results}

The first step consisted of conducting the search in four databases, in which 480 studies were found; the second step consisted of identifying the articles based on the title and abstract, which excluded 250 works that did not contain the inclusion criteria and 208 articles with repeated titles. The third step was the eligibility stage, in which 22 articles were read in full, and the final selection identified four studies which were included in the present review (-Fig. 1).

\section{Characteristics of Included Studies}

All four interventional studies identified (two each from Canada and Korea) included baseline and postintervention results, and had short-period and long-period intervention arms. The Korean study intervention lasted 35 weeks, separated into two phases: 5 weeks $^{16}$ and 30 weeks. $^{17}$ The Canadian study intervention lasted 12 months, also divided into the two-phase investigation: 6 months of intervention and 6 months of no intervention, with both qualitative ${ }^{18}$ and quantitative results ${ }^{19}$ (-Table 1).

\section{Variables Measured and Main Results}

In both studies, physical activity and variables related to psychological, well-being, and cognitive function were measured. Positive effects in both programs were present. ${ }^{16-18}$ In the Canadian study, the physical activity did not increase to levels above those found in the control group ${ }^{19}$ (- Table 2 ). In the Korean studies, the authors reported the results in values with pre- and postinterventions, displayed in - Fig. 2.

\section{Quality and Risk of Bias}

Scores on the PEDro scale ranged from 2 to 9 of a maximum 10 points (-Table 3 ). The Eom et al's studies ${ }^{16,17}$ presented lower scores of quality and bias. Although the eligibility, 


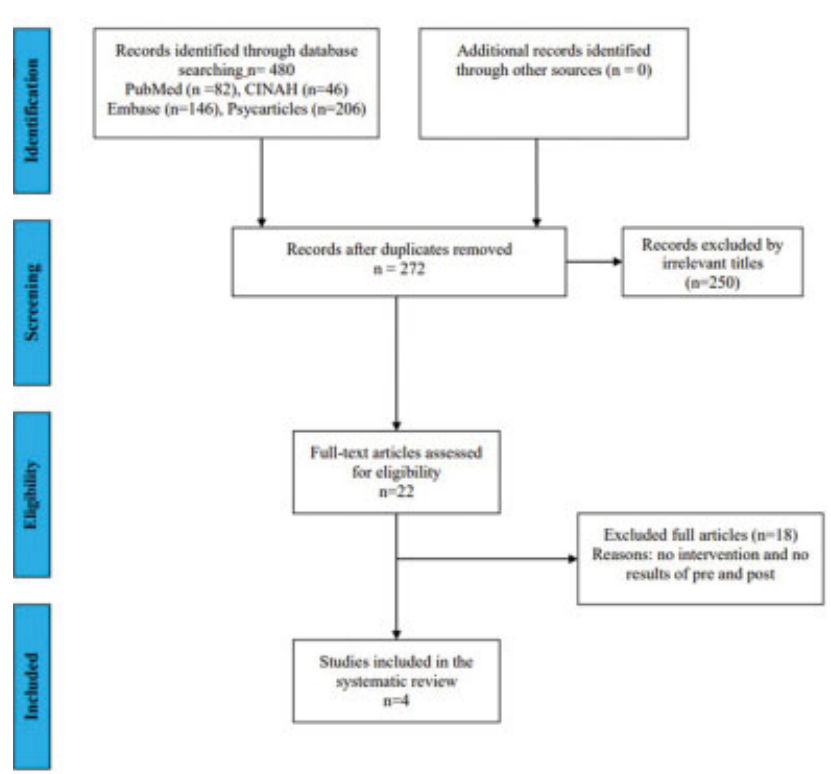

Fig. 1 Preferred Reporting Items for Systematic Reviews and MetaAnalyses diagram.

adequate follow-up, and intention-to-treat analysis criteria were met, the studies did not present comparisons betweengroup and some blinded criteria. Willis et $\mathrm{al}^{18}$ presented a similar weakness and presented the results quantitatively; however, the long-period project demonstrated in Brown et $\mathrm{al}^{19}$ fulfilled most of the quality criteria and showed excellent quality.

\section{Discussion}

This study aimed to review the scientific literature regarding the effect of physical activity intervention in children and adolescents with epilepsy. We found only four studies that presented physical activity intervention, comprising two big projects, a Korean and a Canadian, with a presential sports program, and long-term and home-based exercises recommendation protocols. The exercise improved neurocognitive function, psychological domain, and social interaction in both projects, but not the physical resistance and physical activity levels in this specific population.

In the study of Eom et al from Korea, ${ }^{16,17}$ the program started with 5 weeks of supervised exercise/sports practice in children ( $9.7 \pm 1.42$ years), conducted by exercise experts and assisted by nurses, and continued with 30 more weeks of home-based activities and meetings about exercise instructions. The researchers recommended the parents to encourage their children with epilepsy to perform resistance exercises using body weight and 20 to 30 minutes of aerobic exercise. Similarly, in the Canadian study, ${ }^{18,19}$ the program for children and adolescents (8-14 years) with epilepsy consisted of 6 months of counseling about increased step count, with a goal of 12,000 steps per day, and then 6 more months of only monitoring.

Both study protocols comprised recommendations of physical activity for children and adolescents to encourage them to be more active, but without specific exercise, or protocol controlling type and intensity (e.g., volume and duration), and without professional supervision. Maybe this explains the lack of improvement in the Korean study's physical components ${ }^{15}$ and the failure to increase the physical activity levels in the Canadian study. ${ }^{18,19}$ On the contrary, both protocols improved different parameters such as neurocognitive function, psychological domain, general health and quality of life, and social interaction, highlighting the farreaching benefits of the practice of physical activity, regardless of the type, in children and adolescents with epilepsy.

There was a noticeable lack of information regarding recommendations about appropriate exercises for children and adolescents with epilepsy. In the sport's settings, the literature pointed out that some mechanisms might trigger seizures during athletics, such as sports causing hypoxia which may occur in climbing or skiing at high altitude and sports involving recurring head trauma (e.g., boxing, hockey, diving, soccer, rugby). Moreover, sports with high risk of dangerous falls (e.g., mountain climbing, parachuting) and those who require supervision underwater should be avoided. ${ }^{7}$ Also, Capovilla et $\mathrm{al}^{8}$ categorized the sports based on the risk of injury or death that should a seizure occur during the event: no significant additional risk, moderate risk, and high risk (see detailed in Table 1 of the Capovilla et al's article); nonetheless, the categorization was made based on the judgment of the physician, with no experimental support. On the contrary, the literature also recommends that patients with epilepsy should not be discouraged from practicing any recreational or competitive sport, and they can enjoy the physical and psychological benefits of the sport and exercise as anyone else., 7 Therefore, we highlight the importance of professional teaching, guiding, and monitoring children and adolescents with epilepsy during practice.

The World Health Organization's recent recommendations for physical activity in children and youth aged 5 to 17 years, unless contraindicated due to specific medical conditions, include at least 60 minutes of moderate- to vigorous-intensity exercise daily. Additionally, most of the daily physical activity should be aerobic, strengthen muscle and bone, and should be incorporated at least three times per week. ${ }^{20}$ However, this recommendation has been hard to follow. A recent study demonstrated that globally, more than $80 \%$ of adolescents aged 11 to 17 years did not meet daily physical activity. ${ }^{20}$

Inactive or insufficient active children and youth should be encouraged to a progressive increase in their physical activity levels to eventually achieve the target recommendations and participate in a variety of physical activities to improve their development, and at the same time, these activities should be enjoyable and safe. ${ }^{21}$ For children and adolescents with epilepsy, a supervised and monitored exercise program with their health care and physical education professional should be emphasized to increase physical parameters and physical activity levels, besides the cognitive, psychological, and social benefits. Parents' role is essential to maintain the physical activity levels and other lifestyle factors, as children and adolescents are dependent on them in several aspects.

To date, this is the first systematic review that presents and discusses the protocols and benefits of physical activity 
Table 1 Characteristics of the included studies

\begin{tabular}{|c|c|c|c|c|c|}
\hline Author $(y)$ & Country & $\begin{array}{l}\text { n/age } \\
\text { (median } \pm \\
\text { SD) }\end{array}$ & Epilepsy type & Duration/exercise type & Exercise intervention \\
\hline $\begin{array}{l}\text { Eom et al } \\
(2014)^{16}\end{array}$ & Korea & $\begin{array}{l}\text { Boys }=4, \\
\text { girls }=6 \\
9.7 \pm 1.42 y\end{array}$ & $\begin{array}{l}\text { Benign epilepsy centro- } \\
\text { temporal spikes }\end{array}$ & $\begin{array}{l}10 \text { presential sessions } \\
\text { (twice per week, } 5 \text { wk). } \\
\text { Exercise session dura- } \\
\text { tion: } 3 \text { h. } \\
\text { Home-based exercise } \\
\text { recommendation }\end{array}$ & $\begin{array}{l}\text { Activities consisted of playing } \\
\text { basketball, soccer, table tennis, } \\
\text { badminton, or jump rope, and line } \\
\text { dancing. } \\
\text { Recommendation to perform } \\
\text { home-based exercises, } 15-20 \text { min } \\
\text { of resistance exercises using their } \\
\text { own body weight (e.g., sit-ups and } \\
\text { push-ups) }\end{array}$ \\
\hline $\begin{array}{l}\text { Eom et al } \\
(2016)^{17}\end{array}$ & Korea & $\begin{array}{l}\text { Boys }=4 \\
\text { girls }=6 \\
9.7 \pm 1.42 \text { y }\end{array}$ & $\begin{array}{l}\text { Benign epilepsy centro- } \\
\text { temporal spikes }\end{array}$ & $\begin{array}{l}5 \text { wk of presential activ- } \\
\text { ities } \\
30 \text { wk of home-based } \\
\text { program recommenda- } \\
\text { tion, duration: } 20-30 \\
\text { min }\end{array}$ & $\begin{array}{l}\text { Home-based exercise instruction } \\
\text { for children to perform an exercise } \\
\text { program on their own with their } \\
\text { parents' encouragement at home. } \\
\text { Recommendation consisted of re- } \\
\text { sistance exercises using their body } \\
\text { weight such as sit-ups and push- } \\
\text { ups and 20-30 min of aerobic } \\
\text { exercise }\end{array}$ \\
\hline $\begin{array}{l}\text { Willis et al } \\
(2018)^{18}\end{array}$ & Canada & $\begin{array}{l}\text { Intervention } \\
=56 ; \\
\text { control = } 59 \\
8-14 \text { y }\end{array}$ & $\begin{array}{l}\text { Active epilepsy, with } \\
\text { seizure within the pre- } \\
\text { vious } 12 \text { mo }\end{array}$ & $\begin{array}{l}12 \text { mo of monitoring. } 6 \\
\text { mo of counseling: } \\
\text { weekly for weeks } 1-4 \text {, } \\
\text { biweekly for weeks } \\
6-12 \text {, and monthly for } \\
\text { weeks } 13-24 \text {. A total of } \\
11 \text { calls counseling }\end{array}$ & $\begin{array}{l}\text { Intervention based on achieving a } \\
\text { goal of } 12,000 \text { steps per day. First } \\
6 \text { mo with personal coaching rec- } \\
\text { ommendation regarding increas- } \\
\text { ing step count via phone calls } \\
\text { (intervention group). The second } \\
\text { phase, more } 6 \text { mo, aimed to } \\
\text { maintain the step goal indepen- } \\
\text { dently, without counseling (both } \\
\text { groups) }\end{array}$ \\
\hline $\begin{array}{l}\text { Brown et al } \\
(2019)^{19}\end{array}$ & Canada & $\begin{array}{l}\text { Intervention } \\
=56 ; \\
\text { control = } 59 \\
8-14 \text { y }\end{array}$ & $\begin{array}{l}\text { Active epilepsy, with } \\
\text { seizure within the pre- } \\
\text { vious } 12 \text { mo }\end{array}$ & $\begin{array}{l}12 \text { mo of monitoring. } 6 \\
\text { mo of counseling: } \\
\text { weekly for weeks } 1-4 \text {, } \\
\text { biweekly for weeks } \\
6-12 \text {, and monthly for } \\
\text { weeks } 13-24 \text {. A total of } \\
11 \text { calls counseling }\end{array}$ & $\begin{array}{l}\text { Intervention based on achieving a } \\
\text { goal of } 12,000 \text { steps per day. First } \\
6 \text { mo with personal coaching rec- } \\
\text { ommendation regarding increas- } \\
\text { ing step count via phone calls } \\
\text { (intervention group). The second } \\
\text { phase, more } 6 \text { mo, aimed to } \\
\text { maintain the step goal indepen- } \\
\text { dently, without counseling (both } \\
\text { groups) }\end{array}$ \\
\hline
\end{tabular}

Abbreviation: SD, standard deviation.

Table 2 Variables measured and main results

\begin{tabular}{|c|c|c|}
\hline Study & Measurement & Main results \\
\hline Eom et al $(2014)^{16}$ & $\begin{array}{l}\text { Resistance physical tests; attention, executive } \\
\text { function, depression, anxiety, behavior prob- } \\
\text { lems, and quality of life }\end{array}$ & $\begin{array}{l}\text { Exercise programs show increases from baseline } \\
\text { to postintervention on indices of neurocognitive } \\
\text { function involving visual, auditory, sustained, } \\
\text { and divided attention; psychomotor speed; se- } \\
\text { quential processing; and inhibition-disinhibi- } \\
\text { tion. Ratings of psychological functions also } \\
\text { showed improvement in the realms of emotional } \\
\text { and psychosocial adjustment. Physical tests did } \\
\text { not differ from baseline to postintervention, only } \\
\text { the push-ups test }\end{array}$ \\
\hline Eom et al $(2016)^{17}$ & $\begin{array}{l}\text { Competence, behavioral problems, physical } \\
\text { function, well-being, cognition, social function, } \\
\text { general health, and quality of life }\end{array}$ & $\begin{array}{l}\text { Long-term home-based exercise recommenda- } \\
\text { tion presented significant improvements in } \\
\text { neurocognitive domains such as psychomotor } \\
\text { speed, sustained attention, divided attention, } \\
\text { and inhibition-disinhibition ability, and in psy- } \\
\text { chological domains including internalizing be- } \\
\text { havior problems, general health, and general } \\
\text { quality of life }\end{array}$ \\
\hline
\end{tabular}


Table 2 (Continued)

\begin{tabular}{|c|c|c|}
\hline Study & Measurement & Main results \\
\hline Willis et al $(2018)^{18}$ & $\begin{array}{l}\text { Semistructured interviews with questions per- } \\
\text { taining enhancing PA and how various elements } \\
\text { play a role in facilitation or hindering exercise, in } \\
\text { viewpoints of participants and their parents } \\
\text { PA monitored daily using the Fitbit Ultra Wireless } \\
\text { Activity Tracker }\end{array}$ & $\begin{array}{l}\text { Participant's perspective: weight loss, increased } \\
\text { muscle strength, increased family time, changes } \\
\text { of attitude toward activity, increased insight, } \\
\text { positive feelings associated with achieving goals, } \\
\text { emotional release, change of habits, increased } \\
\text { confidence, changes in time management, im- } \\
\text { proved perception of activity benefits and de- } \\
\text { creased seizure activity. Parents' perspective: an } \\
\text { improved experience of self, strength benefits, } \\
\text { improved sleep, increased family time, changes } \\
\text { in a dialog among families regarding epilepsy, } \\
\text { happier family environment, social benefits, } \\
\text { improved attitude toward PA, change of habits, } \\
\text { changes in perception of benefits of activity, } \\
\text { improved mood, increased confidence, de- } \\
\text { creased seizure activity, increased parents } \\
\text { awareness of own PA, improvement of entire } \\
\text { family's attitude toward activity }\end{array}$ \\
\hline Brown et al (2019) ${ }^{19}$ & $\begin{array}{l}\text { Anthropometric measures, quality of life, and } \\
\text { health-related PA monitored daily using the Fitbit } \\
\text { Ultra Wireless Activity Tracker }\end{array}$ & $\begin{array}{l}\text { The counseling program was unsuccessful in } \\
\text { increasing PA to levels above those found in the } \\
\text { control group. Measures of mental health and } \\
\text { quality of life also showed no differences be- } \\
\text { tween conditions over the 1-year period. In fact, } \\
\text { PA levels decreased among both groups follow- } \\
\text { ing the 6-mo intervention period; however, } \\
\text { reductions in PA were not associated with } \\
\text { declines in depressive symptoms and quality of } \\
\text { life }\end{array}$ \\
\hline
\end{tabular}

Abbreviation: PA, physical activity.

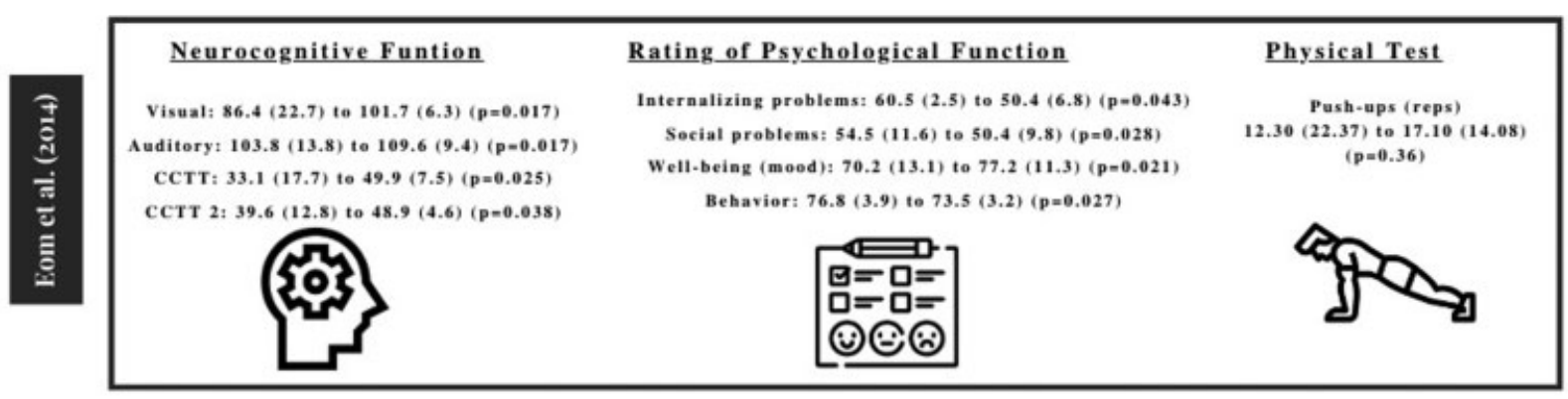

CCTT: Children Color Trail Test 1 (sustained attention); CCTr2: Children Color Trail Test 2 (divided attention, sequential processing, and inhibition-disinhibition); reps: repetitions.

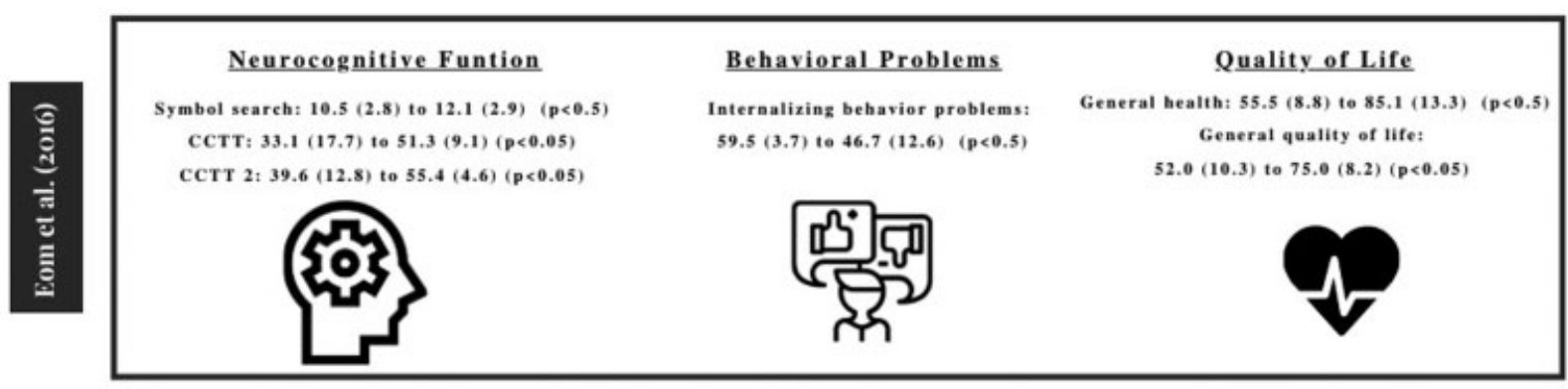

CCTT: Children Color Trail Test 1 (sustained attention); CCTT2: Children Color Trail Test 2 (divided attention, sequential processing, and inhibition-disinhibition.

Fig. 2 Descriptive results of significant variables improved postexercise intervention in children and adolescents from Korean studies. 
Table 3 Quality and eligibility bias of selected studies

\begin{tabular}{|c|c|c|c|c|c|}
\hline & $\begin{array}{l}\text { Eom et al } \\
(2014)\end{array}$ & $\begin{array}{l}\text { Eom et al } \\
(2016)\end{array}$ & $\begin{array}{l}\text { Willis et al } \\
(2018)\end{array}$ & $\begin{array}{l}\text { Brown } \\
\text { et al (2019) }\end{array}$ & $\begin{array}{l}\text { Studies meeting } \\
\text { criterion } \\
n(\%)\end{array}$ \\
\hline Eligibility criteria & Yes & Yes & Yes & Yes & $4(100)$ \\
\hline Randomized allocation & No & No & No & Yes & $1(25)$ \\
\hline Concealed allocation & No & No & No & No & $0(0)$ \\
\hline Comparable at baseline & No & No & No & Yes & $1(25)$ \\
\hline Blinded participants & No & No & No & Yes & $1(25)$ \\
\hline Blinded therapists & No & No & No & Yes & $1(25)$ \\
\hline Blinded assessors & No & No & No & Yes & $1(25)$ \\
\hline Adequate follow-up & Yes & Yes & Yes & Yes & $4(100)$ \\
\hline Intention-to-treat analysis & Yes & Yes & Yes & Yes & $4(100)$ \\
\hline Between-group comparisons & No & No & No & Yes & $1(25)$ \\
\hline Point estimates and variability & Yes & Yes & No & Yes & $3(75)$ \\
\hline Total score & 3 & 3 & 2 & 9 & \\
\hline
\end{tabular}

in children and adolescents with epilepsy. However, despite the originality and robustness of the current study, some limitations should be highlighted. The small number of studies with only two intervention programs included in this review is the most critical limitations. Moreover, the variables evaluated are different as well as methods (e.g., qualitative vs. quantitative). Also, considering the risk of bias, three out of four included studies present poor quality, ${ }^{16-18}$ reported the effects of intervention in the same group (experimental), and thus, these nonrandomized controlled trials compromise the quality of the results. Only one study was considered excellent quality, in which no differences were found in depressive symptoms and quality of life. ${ }^{18}$

Nonetheless, even though the PEDro scale is frequently used in systematic reviews, the interpretation of bias risk requires caution, once the tool is not specific to qualitative studies. Moreover, the selected studies did not report if the physical activity interventions effectively controlled epileptic seizures. Thus, there is a lack of evidence-based literature regarding positive effect of physical exercise in children and adolescents with epilepsy.

\section{Conclusion}

In conclusion, reviewed studies suggest that physical exercise program induces some benefits in children and adolescents with epilepsy. The studies demonstrated positive impact on neurocognitive function, psychological domain, and social interaction, but not on the physical resistance and physical activity levels in this specific population. However, due to low number, poor quality of publications, noncontrolled trials, and varied analyses made (quantitative vs. qualitative) make it difficult to establish consensus about the dose-response of physical activity in epileptics in children and adolescents.

Conflict of Interest

None declared.

\section{References}

1 Beghi E, Giussani G, Sander JW. The natural history and prognosis of epilepsy. Epileptic Disord 2015;17(03):243-253

2 Trinka E, Höfler J, Zerbs A. Causes of status epilepticus. Epilepsia 2012;53(Suppl 4):127-138

3 Carrizosa-Moog J, Ladino LD, Benjumea-Cuartas V, et al. Epilepsy, physical activity and sports: a narrative review. Can J Neurol Sci 2018;45(06):624-632

4 Fernandez-Baca Vaca G, Mayor CL, Losarcos NG, Park JT, Lüders HO. Epileptic seizure semiology in different age groups. Epileptic Disord 2018;20(03):179-188

5 Camfield P, Camfield C. Incidence, prevalence and aetiology of seizures and epilepsy in children. Epileptic Disord 2015;17(02): 117-123

6 Vancampfort D, Ward PB, Stubbs B. Physical fitness levels and moderators in people with epilepsy: a systematic review and meta-analysis. Epilepsy Behav 2019;99:106448

7 Dubow JS, Kelly JP. Epilepsy in sports and recreation. Sports Med 2003;33(07):499-516

8 Capovilla G, Kaufman KR, Perucca E, Moshe SL, Arida RM. Epilepsy, seizures, physical exercise, and sports: a report from the ILAE Task Force on Sports and Epilepsy. Epilepsia 2016;57(01):6-12

9 Pimentel J, Tojal R, Morgado J. Epilepsy and physical exercise. Seizure 2015;25:87-94

10 Iqbal M, Rahman MS, Zafar S, Chen XL, Liu JX, Liu Y. Systematic review and meta-analysis of the efficacy of different exercise programs in pilocarpine induced status epilepticus models. Epilepsy Behav 2017;73:256-267

11 Frucht MM, Quigg M, Schwaner C, Fountain NB. Distribution of seizure precipitants among epilepsy syndromes. Epilepsia 2000; 41(12):1534-1539

12 Vancini RL, Andrade MDS, Vancini-Campanharo CR, Lira CABD. Exercise and sport do not trigger seizures in children and adolescents with epilepsy in school settings. Arq Neuropsiquiatr 2017;75(10):761

13 Liberati A, Altman DG, Tetzlaff J, et al. The PRISMA statement for reporting systematic reviews and meta-analyses of studies that evaluate health care interventions: explanation and elaboration. PLoS Med 2009;6(07):e1000100

14 O'Connor D, Green S, Higgins JP. Defining the review question and developing criteria for including studies. In: Cochrane Handbook for Systematic Reviews of Interventions: Cochrane Book Series. London, UK: Cochrane; 2008:81-94 
15 Silverman SR, Schertz LA, Yuen HK, Lowman JD, Bickel CS. Systematic review of the methodological quality and outcome measures utilized in exercise interventions for adults with spinal cord injury. Spinal Cord 2012;50(10):718-727

16 Eom S, Lee MK, Park JH, et al. The impact of an exercise therapy on psychosocial health of children with benign epilepsy: a pilot study. Epilepsy Behav 2014;37:151-156

17 Eom S, Lee MK, Park JH, et al. The impact of a 35-week long-term exercise therapy on psychosocial health of children with benign epilepsy. J Child Neurol 2016;31(08):985-990

18 Willis J, Hophing L, Mahlberg N, Ronen GM. Youth with epilepsy: Their insight into participating in enhanced physical activity study. Epilepsy Behav 2018;89:63-69
19 Brown DMY, Mahlberg N, Pohl D, et al. Can behavioral strategies increase physical activity and influence depressive symptoms and quality of life among children with epilepsy? Results of a randomized controlled trial. Epilepsy Behav 2019;94:158-166

20 Guthold R, Stevens GA, Riley LM, Bull FC. Global trends in insufficient physical activity among adolescents: a pooled analysis of 298 population-based surveys with 1.6 million participants. Lancet Child Adolesc Health 2020;4(01):23-35

21 World Health Organization. Global action plan on physical activity 2018-2030: more active people for a healthier world. Geneva: World Health Organization; 2018. Licence: CC BY-NC-SA 3.0 IGO 